\title{
Sobre artefato lúdico: a supremacia das bonecas brancas no mercado de brinquedos.
}

\section{The ludic artifact: white doll supremacy in the toy market}

MACIEIRA, Cássia; Doutora; UEMG - Universidade do Estado de Minas Gerais.

cassia.macieira@uemg.br

\section{Resumo}

A supremacia das bonecas brancas da cadeia produtiva industrial de brinquedos aliada à importância desse artefato lúdico pode ser entendida como racista. Nesta pesquisa o método de observação validado foi uma pesquisa de campo em 15 lojas no centro de Belo Horizonte, onde comprovou-se a disponibilidade de bonecas brancas sobre as bonecas negras nas prateleiras, embora a publicidade há anos confirme tal assimetria. O referencial teórico apoiou-se em pedagogos vislumbrando confirmar a boneca como elemento do jogo simbólico e importante na infância. Assim, vislumbrou-se, contudo, uma pretensa solução: a consolidação identitária por meio do aumento da produção de bonecas negras e da diversidade de modelos bem como reivindicar o engendramento das políticas de ações afirmativas na indústria do brinquedo.

Palavras chave: artefato lúdico; design; boneca.

\begin{abstract}
The supremacy of white dolls in the supply chain may be regarded as racist. For this study, the observation methodology was branched out from a field research in 15 stores in central Belo Horizonte, in which the majority of dolls on the shelves and racks had been proved to be white, to the detriment of the offering of black ones. The theoretical framework was based on the work of pedagogues and educators, which aimed at acknowledging dolls as an element in an important childhood symbolic game. Solutions for such an asymmetry were considered: identity consolidation by increasing the production and diversity of black doll models and by conceiving equality concerned public policies and affirmative actions for the toy industry.
\end{abstract}

Keywords: ludic artifact; design; doll. 
A teoria do branqueamento no Brasil, o esforço em vender a imagem do país como um território mestiço, sincrético e espetacular, a reivindicação da democracia racial visando ao apagamento histórico, o número de mortes de jovens negros registrado no Mapa da Violência ${ }^{1}$, tudo isto configura o contexto de um país que, ontem e hoje, comercializa mais bonecas brancas do que negras. Pretende-se, neste trabalho, criticar a primazia da cadeia produtiva industrial de brinquedos diante da importância do artefato lúdico 'boneca' (imbuído de valor material e imaterial), e promover a relevância do design como campo que agrega iniciativas e reconhece a premência de se produzir brinquedos considerando a identidade - aqui priorizada a partir das relações étnicoraciais.

(...) dos 1945 modelos de bonecas encontrados nos sites das fabricantes, apenas 131 são negras. Já entre as varejistas online, apenas 3\% das bonecas disponíveis para compra são negras. A pior situação foi verificada no site das Lojas Americanas, em que, de 3030 bonecas, apenas 18 eram negras. Já no site da Ri Happy foram encontrados 17 modelos negros entre 632 bonecas e, no Walmart, entre 835, 20 eram negras. $^{2}$

A Mattel ${ }^{3}$ introduziu no mercado mundial, em 1981, uma boneca coadjuvante da linha Barbie: a "amiga negra da Barbie", três décadas após o lançamento da boneca loura. Esta fabricante e outras empresas, ao explorarem o multiculturalismo através de produtos secundários (amiga negra), confirmam a superficialidade da relação com a cultura de seus consumidores; não por falta de mapeá-los, mas de conhecê-los: “(...) em 42 anos de existência, a venda da boneca Barbie está estimada em mais de um bilhão de exemplares, em 150 países. Isso significa que duas Barbies são vendidas por segundo no mundo". ( MEFANO, 2005, p.13). Produto persistente de venda, sempre teve um consumidor ávido e constantemente estimulado, sobretudo nos Estados Unidos, país de origem da empresa: "somente em 1991, quando a Mattel legitimou esse mercado lançando três bonecas negras de tons diferentes de pele, as vendas aumentaram (...)".( ROVERI, 2008, p.67). Não por acaso, a indústria acompanhava o contexto da década de 1990, quando houve o aumento populacional e do poderio financeiro das famílias negras e hispânicas norte-americanas." ( ROVERI, 2008, p.67-68).

[...] já a Abrinq considera que a porcentagem atual de bonecas negras no mercado é uma vitória. 'Há 10 anos não havia bonecas negras no Brasil. A participação era zero.

\footnotetext{
${ }^{1}$ http://www.mapadaviolencia.org.br/ . Acesso em:20/02/2018.

${ }^{2}$ FREITAS, Hindara. Apenas 3\% das bonecas no mercado são negras, aponta estudo. Disponível em: <http://emais.estadao.com.br/noticias/comportamento,apenas-3-das-bonecas-no-mercado-sao-negras-apontaestudo,10000085868>. Acesso em:20/02/2018.

3 Fabricante americana da boneca Barbie, representada durante muitos anos pela empresa brasileira Estrela Manufatura de Brinquedos Estrela S.A., surge em 1937, no Brasil.
} 
Conseguimos elevar esse número para 3\%, o que consideramos uma vitória. Os sinais de mercado indicam que essa demanda pode ser crescente, e a indústria brasileira de brinquedos está preparada para atendê-la', declarou Synésio Batista da Costa, presidente da Associação. ${ }^{4}$

Sobre o fenômeno 'consumo' sabe-se que, muitas vezes, a decisão da compra do brinquedo é do adulto, não obstante seja influenciado pelos filhos; assim, é responsabilidade de ambos o protagonismo de bonecas brancas no mercado. Pergunta-se: a oferta assimétrica de bonecas brancas determina o consumo e posiciona o consumidor como passivo ou o mercado produz porque há demanda? Afinal, o consumidor pode ser "irracional, supersticioso, tradicionalista ou experimental: a essência do conceito de consumidor individual do economista é que ele exerce uma escolha soberana".(DOUGLAS, M.; ISHERWWOOD, B., 2004, p.101) Então, considerando a perspectiva da Economia, é válido pensar que a cadeia produtiva de brinquedos não é austera, autoritária, negligente e tampouco exerce uma autonomia suprema? Para a Antropologia do Consumo:

A necessidade de ser capaz de escolher racionalmente num mundo inteligível é simplesmente uma extensão do conceito de racionalidade econômica. Sem ela, todas as outras suposições do conceito são muito pouco. Todos os demais seres vivos submetem sua experiência a um referencial organizador especifico da espécie, referencial esse que restringe o âmbito das mensagens e respostas possíveis. Mas a racionalidade humana não se submete. Ela negocia as estruturas organizadoras. A experiência humana pode correr para uma grande variedade de possíveis quadros de referências, pois o ser humano racional é responsável por recriar continuamente um universo em que a escolha possa acontecer. Dar sentido ao mundo envolve interpretar o mundo como sensível. Uma vez concedido a isso, a pergunta de por que as pessoas querem os bens pode transformar-se em algo como uma abordagem da informação. Mas é um exercício bem diferente do da análise econômica que conta o custo da informação como parte do custo da produção. ( DOUGLAS, M.; ISHERWWOOD, B., 2004, p.120)

Se o mercado de brinquedos tivesse, há décadas, um histórico marcado por disponibilizar muitas e diferentes referências projetuais (estética), estimulando a diversidade, o pertencimento e valores identitários, as bonecas brancas seriam preteridas pelo consumidor ${ }^{5}$ ? Não seriam elas apenas mais uma referência estética para que as crianças se reconheçam em diferentes contextos, sem as limitações impostas pelo mercado e a sociedade? Uma sociedade balizada predominantemente por bonecas brancas pressupõe diversos fatores, incluindo a reverberação do neocolonialismo; porém, tal constatação pode ser ingênua para os economistas que defendem uma teoria moralmente neutra do consumo. Segundo Canclini: "em quase todo tipo de consumo está claramente presente um conjunto de dimensões estéticas, de sentidos sociais e antropológicos, que às vezes é ocultado pela publicidade e pela redução da diversidade de significados a uma função única." 6

\footnotetext{
${ }^{4}$ FREITAS, op. cit.

${ }^{5}$ A pesquisa de campo sobre a supremacia das bonecas brancas nas prateleiras de lojas de brinquedos, no centro, em Belo Horizonte ocorreu no mês de fevereiro e março de 2018.

${ }^{6}$ Disponível em: <https://www.edusp.com.br/cadleitura/cadleitura_0802_8.asp>. Acesso em: 20 fev. 2018.
} 
Percebe-se que muitas experiências estão marcadas por discursos e ações deturpadas em relação à cor, gênero e etnia. Em Relações étnico-raciais e educação infantil: ouvindo crianças e adultos, as educadoras, ao proporem o diálogo com os campos das relações étnico-raciais e da educação infantil, reforçam que "adotar a igualdade como princípio não significa a eliminação da diferença, mas o seu reconhecimento". (SOARES, 2017, p. 25) Foi percebido pelas pesquisadoras que, no ambiente escolar, quando da escolha de livros e de brinquedos e do cuidado com os aspectos estéticos (cartazes escolares) ocorre prioritariamente a representação do grupo branco, e isso certamente "impede as crianças negras ou de outro grupo construírem o sentimento de pertença ao seu grupo étnico-racial."

A repetição de qualquer boneca representando personagens heroínas louras como padrão de beleza, especialmente em um país miscigenado ${ }^{8}$, leva ao desentendimento da criança sobre seu próprio corpo, confirmando novamente a urgência de se estimular o pertencimento e os valores identitários: "vivemos em uma nação em que uma sutil maioria da população é composta de pretos e de pardos (que, somados, constituem a categoria 'negros'). Entre os demais, a maior parte são brancos miscigenados." 9

Para Jean Piaget (1975), à medida que a criança cresce e se adapta à realidade física e social, percebe-se um enfraquecimento do seu simbolismo lúdico. A criança transforma, substitui, compartilha, engendra-se a regras e também passa a representá-las, imitando-as. $O$ autor defende que o jogo de regras marca a transição da prática da atividade individualizada para a socializada, que se manterá durante a fase adulta (outros jogos lúdicos). Esta inserção da criança no mundo a faz encontrar seu lugar de onde operar, propiciado pelas primeiras experiências (potencial/imaginário) e preenchido, inicialmente, por um objeto transicional. É nesse espaço criado na primeira infância - do "aceitar estar sozinho" - que virá alojar-se a experiência cultural e artística: "se o objeto transicional perde sua significação, é porque os fenômenos transicionais tornam-se difusos e se estendem por todo o domínio cultural." ( WINNICOTT, 1975, p.13)

A transição piagetiana "individualizada para a socializada" precedida pelo "objeto transicional" de Winnicott, responsável pelo alojamento de experiências, afirma a importância da qualidade (natural) das brincadeiras praticadas bem como as escolhas dos objetos (brinquedos) da infância. Por isso, é fundamental o entendimento do desenvolvimento sensório-motor da criança na criação de objetos que the serão oferecidos, pois o brinquedo é um instrumento facilitador do desenvolvimento infantil.

\footnotetext{
7 , p.24.
}

${ }^{8}$ Veja a resposta da Empresa nacional Estrela em fevereiro de 2018: "Sou professora e estou escrevendo um artigo sobre a recepção das bonecas negras no mercado. Gostaria da ajuda de vocês sobre o ano de fabricação da primeira boneca negra .... agradeço desde já. prof. Cássia." RESPOSTA: Olá Prof. ${ }^{\circ}$ Cássia.//Agradecemos o seu contato com a Estrela! Estrela é a indústria pioneira em bonecas negras e também a que mais lançou estas bonecas no mercado até hoje. Começamos essa fabricação ente os anos de 1940 à 1950. Em linha este ano nós temos a boneca Meu Bebê Negra e a coleção Adunni que pode ser encontrada exclusivamente nas lojas Ri Happy. Conte sempre conosco,Centro Estrela de Atendimento ao Consumidor facebook.com/BrinquedosEstrela www.estrela.com.br 0800-704-5520

9 Por que ensinar relações étnico-raciais e história da África nas salas de aula? Disponível em: $<$ https://ensaiosdegenero.wordpress.com/2014/03/19/por-que-ensinar-relacoes-etnico-raciais-e-historia-da-africanas-salas-de-aula/>. Acesso em: $21 \mathrm{fev} .2018$. 
$\mathrm{Na}$ infância, a brincadeira é fonte de desenvolvimento e linguagem: o imbricamento entre o desejo da criança e a realidade objetiva é que proporciona o acesso ao lúdico, acionado pela imaginação. São as brincadeiras que abrem espaços para o jogo da linguagem com a imaginação, configurandose como possibilidade de forjar novas formas de conceber a realidade social e cultural, além de servir como estrutura na construção de conhecimentos e valores. Os brinquedos ganham vida através da relação entre sujeito e objeto - única para cada indivíduo, fazendo referência ao seu contexto, história e cultura, entrelaçados pela linguagem. Assim, a criança recria a realidade através da utilização de sistemas simbólicos próprios.

Para Vygotsky (1984), a atividade lúdica está entre o desejo de agir sobre o objeto e o domínio das atividades para a execução dessa ação. O entendimento do objeto relacional apoia-se, conforme certifica Vygotsky, no fato de que a humanização se dá a partir de dois elementos básicos: o instrumento e o signo. Enquanto o instrumento age sobre os objetos, o signo agiria sobre o psiquismo. Portanto, é a linguagem a mediadora dos signos produzidos pela cultura; e esta se configuraria como o lugar de interações, negociações. Mais importante ainda: a linguagem possibilita a criança operar na ausência do objeto (autonomia). (WINNICOTT, 1975, p.13). A brincadeira deve ser uma atividade própria e, não, instrumento para outro objetivo. Tal defesa é do pedagogo Winnicott: o jogo e a brincadeira são atos criativos e livres que emanam do indivíduo e, não, da sociedade, seja através de regras estabelecidas ou de uma organização.

Enfim, para Gilles Brougère (1995), em Brinquedo e cultura, quando a criança se apropria do objeto (brinquedo) sua função e símbolo estão na maioria das vezes completamente ligados e são indissociáveis:

o brinquedo oferece um universo estruturado e completo no qual a criança pode mergulhar, pode-se introduzir. Percebemos, assim, uma autonomia do mundo do brinquedo que produz sua própria lógica. É preciso, também, levar em conta o impacto da dimensão funcional sobre a representação: a função pode, efetivamente, ter incidências sobre a própria forma de representação. ( BROUGÈRE, 1995, p.44)

Nesse sentido, a incidência sobre a forma de representação é que deve ser criticada com vistas à dissimulação ideológica das estratégias mercadológicas da indústria de brinquedos. Torna-se prioritário entender o brinquedo, elemento do jogo simbólico (mediador), nesse lugar. Brougère assegura que "a aprendizagem é ativa no sentido de que não se submete às imagens, mas aprende a manipula-las, transformá-las e até mesmo praticamente negá-las." ( BROUGÈRE, 1995, p.49) O fulcro da questão é que a primazia das bonecas brancas não permite que a criança tenha escolha, sobretudo diante de um contexto homogeneizado, impedindo, então, a percepção sobre a diferença.

No Brasil, há dois órgãos atinentes a brinquedos: Abrinq (Associação Brasileira dos Fabricantes de Brinquedos) e o Inmetro (Instituto Nacional de Metrologia, Qualidade e Tecnologia). Todo brinquedo, independente se é fabricado no país ou não precisa ser certificado pelo Inmetro. As 
avaliações "são determinadas de acordo com o tipo do brinquedo e baseadas na composição dos materiais utilizados pelo produto, na avaliação da intenção do uso e na forma de utilização do brinquedo pela criança" ${ }^{10}$. Já a Abrinq é uma entidade de classe de representação oficial da indústria e do setor de brinquedos, cujo objetivo é defender os "interesses da classe em todos os fóruns, nacionais e internacionais, dentro dos melhores preceitos éticos" ${ }^{11}$, representando a maioria dos fabricantes de brinquedos do país que aprovam o Código de Ética e Conduta da Indústria de Brinquedos.

Percebe-se que a tão necessária interação entre design e indústria aconteceu de forma consideravelmente tardia no Brasil; a indústria não deu ao design brasileiro, como antes se esperava, uma legitimidade que the proporcionasse um maior e veloz desenvolvimento no âmbito produtivo local. A distância existente entre designers e empresas nos deixou à margem da competição mundial no campo do design e dos artefatos industriais. ( MORAES, 2006, p.41)

A indústria, ao repetir os brinquedos de sucesso das feiras internacionais visando às vantagens comerciais (licenciamentos), atua de forma autoritária na medida em que impõe brinquedos ao mercado brasileiro; ainda que correspondam às exigências do Inmetro, tais brinquedos não privilegiam a cultura brasileira. Não se trata, ainda, da reivindicação de bonecas criadas a partir da riqueza regional (local/global) e da proibição total à importação. Queremos instigar, primeiramente, a consciência de que a homogeneização a partir da predileção de bonecas loiras no mercado de brinquedos é impositiva. A consonância com a cultura brasileira dar-se-ia, de imediato, mediante a recusa da homogeneização. A conquista de uma produção de bonecas com vistas à diversidade não se deveria restringir ao atendimento de demandas; antes, é necessário considerar a homogeneização uma prática desestabilizadora e racista.

É da metodologia do design propor o diálogo, buscando alcançar uma relação direta do designer com o público para escutá-lo, entendê-lo, e mapear suas necessidades. Tal prática não soluciona o controle de todas as variáveis do processo (conceituação, projeto, produção, distribuição e descarte), porém permite uma mudança no ambiente embrutecedor da indústria. Outra alteração significativa seria a inserção de uma gestão em design durante todo o processo.

O designer nem sempre está no controle da situação do projeto, e por isso dificilmente consegue validar sua ideologia e pressupostos éticos, não obstante no século XXI o design esteja amplamente relacionado à inovação e à humanização.

Sendo uma atividade historicamente pouco formalizada e valorizada no país, o design não foi amplamente praticado na indústria brasileira que, voltada a atender as demandas internas de um mercado ainda em crescimento, adaptando, assim, produtos

\footnotetext{
${ }^{10}$ http://www.inmetro.gov.br/imprensa/releases/brinquedo2.asp

${ }^{11}$ http://www.abrinq.com.br/QuemSomos.aspx
} 
estrangeiros, não sentia necessidade de investimentos dedicados ao desenvolvimento de produtos inéditos [...]. A indústria de brinquedos nacional cresceu com poucas referências em design e em design de brinquedos. ( FERNANDES, 2016, p.16)

O designer partilha do caráter sistêmico, questionando o que está envolvido em cada projeto, além da forma e função dos artefatos. Também prevê o controle da complexidade, uma vez que se apoia em "um conjunto de informações sobre contexto sociocultural, mercado, sustentabilidade ambiental, fatores produtivos e tecnológicos que o ajudará das decisões no decorrer das fases metodológicas." ( CARVALHO, J.; MONTE, L.; MOTA; N., 2017, p.151)

O designer, ao planejar e conceber artefatos, atribui aos objetos de uso cotidiano significados, fazendo com que o artefato não seja nunca um objeto neutro e isolado de seu contexto de uso. Os artefatos produzidos pelo ser humano vão muito além da própria materialidade, pois dizem respeito às relações que as pessoas mantêm com eles. Por meio das relações sociais em que estão envolvidos, os artefatos adquirem significado que podem estar relacionados tanto aos aspectos funcionais do produto quanto aos valores simbólicos a eles atribuídos. (MEFANO, 2005, p.81-83)

Em Design e identidade: estudos de caso aplicado ao Brasil, o autor defende: "faz-se necessário reconhecer a identidade como um elemento que necessita das intenções dos sujeitos e das relações sociais para ser construída e estabelecida", ( CARVALHO, 2012, p.14) pois nesse lugar também reside a necessidade da proteção aos indivíduos, objetivando a preservação de suas características.

No combate à hegemonia de bonecas brancas no mercado brasileiro, o design "pode ser entendido como um elemento capaz de fomentar iniciativas que possam modificar substancialmente a realidade, contribuindo na promoção e valorização de identidades de produtos locais." ( CARVALHO, 2012, p.36) Tal lógica metodológica distancia-se da prática comercial repetida há décadas, como nos moldes da importação de bonecas da Mattel e, hoje, como toda terceirização no continente asiático. No Brasil, mesmo que sejam recentes as discussões e lutas antirraciais, vêse a vitória do movimento negro contra o racismo, e em prol da valorização de identidades.

Enfim, sobre o modo assimétrico de produção x recepção de bonecas brancas é coerente reivindicar que os impactos da Lei no $10.639 / 03^{12}$ que estabelece a obrigatoriedade do ensino da história e cultura afro-brasileira e africana nas escolas públicas e privadas do Ensino Fundamental e Médio reverberem no cotidiano familiar, nas comunidades e nas escolhas frente à dominação cultural. Que as políticas de ações afirmativas - na busca da equidade, capaz de "reverter a representação negativa dos negros para promover igualdade de oportunidades e para combater o preconceito e o racismo"13 - sejam premissas, inclusive para as regulamentações do Inmetro, prosperando brinquedos democráticos, fundamentados nas diferenças mediadas por empresários, fabricantes, distribuidores, lojistas, importadores e atacadistas. Reivindicar uma produção de bonecas negras,

\footnotetext{
${ }^{12}$ http://www.planalto.gov.br/ccivil_03/Leis/2003/L10.639.htm

${ }^{13}$ http://www.seppir.gov.br/assuntos/o-que-sao-acoes-afirmativas
} 
evocando a identidade nacional, requer também solicitar uma demanda de autonomia para o design.

O artefato industrial (brinquedo) bem apropriado pela indústria por sua dimensão simbólica (valores tangíveis e intangíveis) nunca deixará de ser comercializado, devido à grande procura. Além disso, tomando o consumidor como autônomo, livre das artimanhas da publicidade, deveria ser iniciativa da Abrinq, como órgão que defende "melhores preceitos éticos", garantir ao consumidor uma gama de produtos e iniciativas consoantes com a diversidade sociocultural brasileira. Todavia, a realidade é outra:

A linguagem do design é diferente da linguagem da indústria. Seguidamente são destinadas a uma incompreensão recíproca. A solução é aquela que eu chamo 'orientação demo'. Como demo entendo aquele modelo, ou protótipo, ou então aquelas ações que mostram à empresa o que podem fazer juntos. É uma espécie de evangelização: partir com pequenas parábolas para mostrar à empresa o que pode obter com esta profícua colaboração. ( ZURLO, 2006, p.22)

Essa diferença de linguagem entre o design e a indústria, no que se refere especificamente à produção de bonecas leva-nos a constatar que uma ação conjunta totalmente orquestrada ainda é utopia. De forma reducionista, a indústria justifica a inserção de aspectos identitários em seu modelo de produção acelerado apenas quando reconhece dados de compra digital. Ou seja, se não há demanda de bonecas negras pelo consumidor deve-se manter a repetição dos modelos de bonecas brancas. O que se difere do design, na busca de desafios:

\footnotetext{
Embora se tenha uma variedade de alternativas metodológicas e projetuais para a caracterização da identidade, [...] a inserção de aspectos identitários ainda é reconhecida como um desafio para as práticas de design. As dificuldades se apresentam tanto nas ações para imprimir aspectos identitários aos produtos, quanto às limitações de se sustentar tais características, a fim de serem reconhecidas pelos usuários em contextos diferentes. ( CARVALHO, 2012, p.103)
}

Por fim, além da mudança do comportamento de consumo coletivo, vislumbram-se mudanças na assimetria de bonecas brancas $x$ bonecas negras, e a contextualização identitária via modo explícito: aumento da produção de bonecas negras e da diversidade de modelos; gestão do design na indústria (não embrutecimento) somada ao engendramento das políticas de ações afirmativas na indústria do brinquedo (democracia). Sempre com vistas que tais soluções repercutam em outros setores e estimulem novas práxis e respostas criativas dos agentes, preferencialmente imediatas, para as solicitações do meio social em questão.

\section{Referências:}

ALANA, Instituto. Criança e consumo. Entrevistas. A importância do brincar. (introdução). Disponível em: <http://criancaeconsumo.org.br/wp-content/uploads/2014/02/Crian\%C3\%A7a-e- 
Consumo-Entrevistas-Vol-5.pdf>. Acesso em: 28 fev. 2017.

APPADURAI, Arjun. Introdução: mercadorias e a política de valor. In: A vida social das coisas: as mercadorias sob uma perspectiva cultural. Niterói: Ed. UFF, 2008.

BONSIEPE, Gui. Design, cultura e sociedade. São Paulo: Blucher, 2011.

BRASIL. Diretrizes Curriculares Nacionais para a Educação das Relações Étnico-Raciais e para o Ensino da História Afro-Brasileira e Africana. Brasília: SECAD/ME, 2004.

BROUGÈRE, Gilles. Brinquedo e cultura. São Paulo: Cortez, 1995.

CARVALHO, Alecir Francisco de. Design e identidade: estudo de casos aplicados ao Brasil. Dissertação (Mestrado em Design). Universidade Estadual de Minas Gerais, Belo Horizonte, 2012.

CARVALHO, Juliana; MONTE, Luiz; MOTA; Nathalie. Metaprojeto como instrumento de gestão da complexidade no Design. In: ARRUDA, Amilton J. V. (org.). Design e complexidade. Série: [Design Contexto] Ensaios sobre Design, Cultura e Tecnologia. Versão eletrônica. São Paulo: Blucher, 2017, p. 19-20.

CASCUDO, Luís da Câmara. Civilização e cultura. Rio de Janeiro: José Olympio, 1988, v. II, p. 300303.

DOUGLAS, M.; ISHERWWOOD, B. 0 mundo dos bens: uma antropologia do consumo. Rio de Janeiro: Ed. UFRJ, 2004.

FERNANDES, Florestan. O negro no mundo dos brancos. São Paulo: Global, 2007.

FERNANDES, Rodrigo Queiroz Kühni. A gestão do design na indústria de brinquedos: estudos de caso sobre a inserção do design no processo de desenvolvimento de produtos em empresas de brinquedo no Brasil. Dissertação (Mestrado em Design). Universidade Federal de Pernambuco, Centro de Artes e Comunicação, 2015.

INGOLD, Tim. Trazendo as coisas de volta à vida: emaranhados criativos num mundo de materiais. Disponível em: <http://www.scielo.br/scielo.php?script=sci_arttext\&pid=S010471832012000100002\&lng=en\&nr m=iso>. Acesso em: 20 jan. 2018.

MEC - Ministério da Educação. http://portal.mec.gov.br/index.php?option=com_docman\&view=download\&alias=10098diretrizes-curriculares\&ltemid=30192

MEFANO, Ligia. Design de brinquedos no Brasil: uma arqueologia do projeto e suas origens. Dissertação. Mestrado. Departamento de Artes \& Design da PUC-Rio, Rio de Janeiro, 2005.

MORAES, Dijon de. Análise do design brasileiro: entre mimese e mestiçagem. São Paulo: Blucher, 2006.

PIAGET, Jean. A formação do símbolo na criança: imitação, jogo e sonho, imagem e representação. Tradução de Álvaro Cabral e Cristiane Monteiro Oiticica. Rio de Janeiro: Zahar, 1975.

ROVERI, Fernanda Theodoro. Barbie: tudo o que você quer ser... ou considerações sobre a educação de meninas. Dissertação (Mestrado em Educação). Universidade Estadual de Campinas, Faculdade de Educação, São Paulo, 2008. 
SOARES, Lucineide Nunes; SILVA, Santuza Amorim da. Relações étnico-raciais e educação infantil: ouvindo crianças e adultos. Belo Horizonte: Ed. UEMG, 2017.

VYGOTSKY, L. S. A formação social da mente. São Paulo: Martins Fontes, 1984.

WINNICOTT, D. W. O brincar \& a realidade. Rio de Janeiro: IMAGO, 1975.

ZURLO, Francesco. Carregamos os objetos de significado, afetividade, vida psíquica. São Leopoldo, 2006, p.

Disponível

em:

<http://www.ihuonline.unisinos.br/media/pdf/IHUOnlineEdicao189.pdf >. Acesso em: 08 jan. 2010. 